\title{
Optimization Practice of Gas Extraction Technology for Long Distance
}

\author{
Protected Layer
}

\section{Siqian ${ }^{1,2, a}$ Li\&Zunyu Xu1,2\&Benqing Yuan ${ }^{1,2}$}

\author{
${ }^{1}$ Chongqing Resear Institute of CO.,Ltd of China Coal Technology Engineering \\ Group,Chongqing,China
}

${ }^{2}$ State Key Laboratory of Gas Disaster Monitoring and Emergency Technology

aCorresponding author e-mail:siqian_licqmk@163.com

Key words : Protected layer ; Pressure relief gas ; Gas control; Surface drilling

\begin{abstract}
Through the analysis of the gas control effect of the mine protected layer, it was shown that the combination of surface drilling and downhole through-layer drilling can solve the problem of pressure relief gas emission of the protected layer and avoid the gas overrun accident in the working face of the protected layer, but the two extraction methods have mutual influence and the gas control cost is larger. On the basis of field investigation on the drainage radius of surface drilling, the layout of through-layer drilling was optimized, and It is put forward that the pressure relief gas of the protective layer is controlled by the way of surface drilling drainage and through-layer drilling drainage, which reduced the cost of gas control, realized the efficient and safe mining of protective layer, and had certain guiding significance for mine gas control under similar conditions.
\end{abstract}

\section{Introduction}

With the increasing of coal mining depth and intensity, coal and gas outburst disasters become increasingly prominent. According to the domestic and foreign theoretical research and mining practice, mining protective layer and pre-extraction of coal seam gas is an effective regional measures to prevent and control coal and gas outburst. The prevention and control of coal and gas outburst regulations pointed out that in order to avoid the protective layer mining is a large number of gas gushed out of the protective layer mining protective layer at the same time of pre-extraction by protective layer gas. In coal mine production practice, it is impossible to solve the problem of mine gas by a single gas extraction method, often need a combination of various ways to achieve the comprehensive extraction of mine gas ${ }^{[1 \sim 3]}$.

In this paper, through the analysis of the effect of gas drainage by protective layer of mine, optimized the layout of underground through-hole drilling, using surface drilling drainage, through-hole drilling auxiliary drainage way can ensure the safe mining of protective layer working face, at the same time reduce the cost of gas control, improve mine efficiency, provide theoretical support for mine gas drainage by protective layer. 


\section{Engineering Background}

11-2,13-1 coal seam of Zhujixi mine is stable near horizontal coal seam, the average thickness

of $1.6 \mathrm{~m}, 3.8 \mathrm{~m}$, respectively, the average angle of 6 ,spacing of $70 \mathrm{~m}$.they are coal and gas outburst coal seam. According to the measured gas parameters and adjacent mine production practice, 11-2 coal seam outburst risk is smaller than 13-1 coal seam, the mine will be 11-2 coal seam 13-1 coal seam key protective layer mining. 11-2 coal seam first mining adopts the arrangement of "one side five lane", namely the track along the trough and floor lane, transportation along the trough and floor lane and roof lane; Floor lane arrangement in 15 20 $\mathrm{m}$ position from the bottom, out-of-plane fault working face gateway distance is $18 \sim 20 \mathrm{~m}$, roof lane is located in the coal seam floor $35 \sim 45 \mathrm{~m}$, in-plane fault track gateway $64.2 \mathrm{~m}$. The working face layout plan and coal seam occurrence profile as shown in figure 1, figure 2.

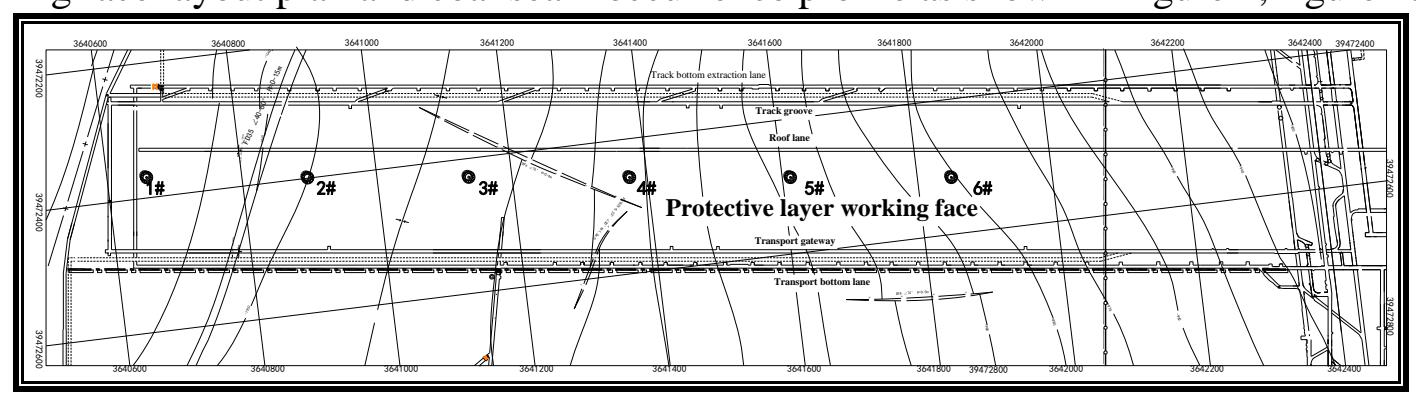

Fig. 1 Mining face layout plan

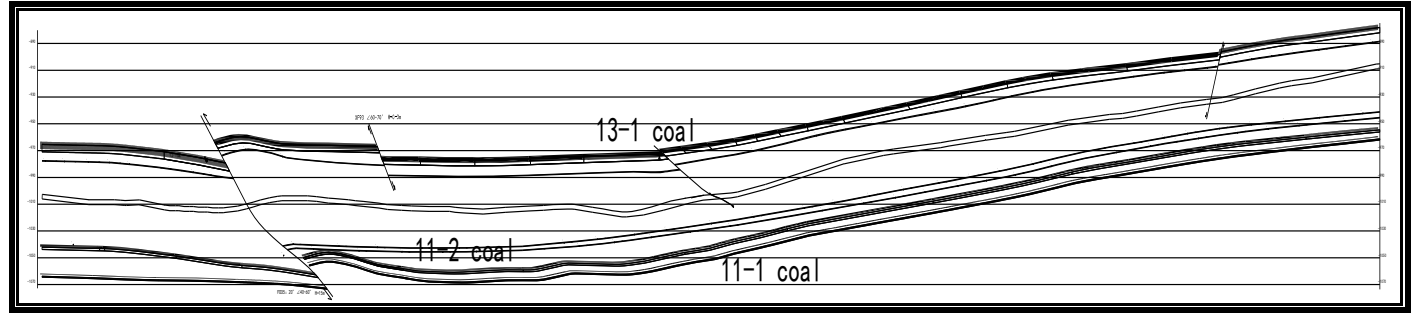

Fig. 2 11-2 , 13-1 coal seam occurrence profile

\section{Gas Drainage Design of Protected Laye}

Extraction Design Reference. According to the source prediction method ${ }^{[1,2]}$ calculation of protective layer working face gas emission amount of $31.2 \mathrm{~m}^{3} / \mathrm{min}$, among them, the coal seam gas emission amount of $10.5 \mathrm{~m}^{3} / \mathrm{min}$, adjacent layer gas emission amount is $20.7 \mathrm{~m}^{3} / \mathrm{min}$, working face gas mainly comes from the adjacent layer of pressure relief gas. Working face design with air volume is $1500 \sim 1680 \mathrm{~m}^{3} / \mathrm{min}$, the maximum amount of wind exhaust gas is $12 \sim 13.44 \mathrm{~m}^{3} / \mathrm{min}$, ventilation alone is difficult to solve the problem of gas in the working face, therefore, the protective layer during mining to strengthen the gas drainage by protective layer. According to the law of overlying strata movement after the mining of the lower protective layer and the gas extraction experience of the adjacent mine protected layer, the protected layer adopts the combination of surface drilling and through-layer drilling to extract the gas of the protected layer.

Surface Drilling Drainage Design.After the protective layer is mined, the overlying coal strata on the working face move, deform and collapse, forming a caving zone, a collapse zone and a bending subsidence zone, wherein the coal strata in the region have developed fissures 
and increased air permeability; under the action of extraction negative pressure, the pressurerelief gas can flow along the parallel bedding direction or along the vertical and oblique bedding direction, and a large amount of pressure-relief gas is extracted ${ }^{[3 \sim 5]}$. The principle diagram of surface drilling and drainage for lower protective layer mining is shown in fig. 3 . According to the protective layer working face coal seam occurrence and roadway layout, working face in the middle of the inclined direction design layout of six ground drilling, spacing of $240 \mathrm{~m}, 1$ \# drilling $50 \mathrm{~m}$ away from the working face cut, 6 \# drilling is about 230 $\mathrm{m}$ away from the stop line ( as shown in figure 1). Final hole is located in 11-2 coal seam roof $15 \mathrm{~m}$, main drainage 13 - 1 coal seam pressure relief gas and 11-2 coal seam fissure zone Nevas. The surface drilling profile is shown in figure 4.

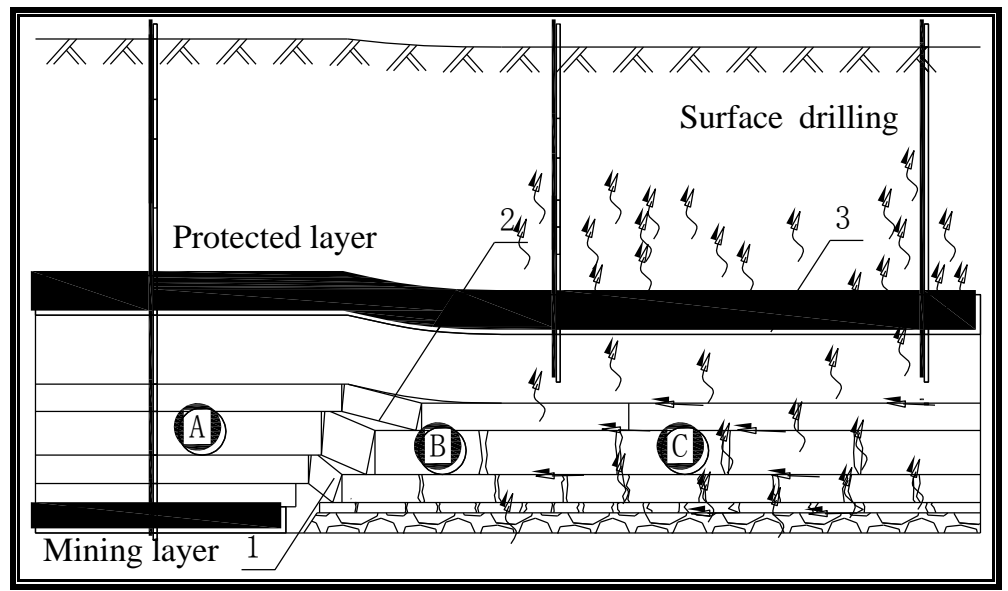

Fig. 3 Schematic diagram of ressure relief extractionprinciple for surface drilling

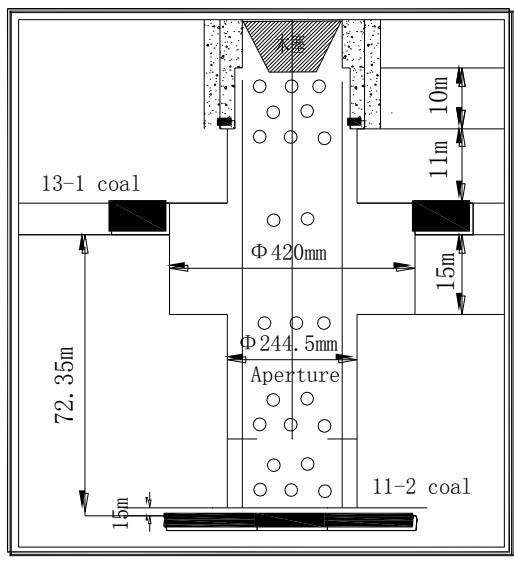

Fig. 4 Schematic diagram of surface drilling section

Drainage Design of Through-Hole Drilling. According to the working face roadway layout, in the roof lane construction drilling hole diameter $108 \mathrm{~mm}$ through layer drilling drainage 13-1 coal seam gas, row spacing between $20 \mathrm{~m} \times 40 \mathrm{~m}$, in working face cut corresponding area drilling spacing is $10 \mathrm{~m}$, drilling control range for protective layer work face should be 13-1 coal seam area. In combination with the site construction conditions, the area around 50m and below the surface drilling will not be drilled through the layer. Drilling layout plan as shown in figure 5 .

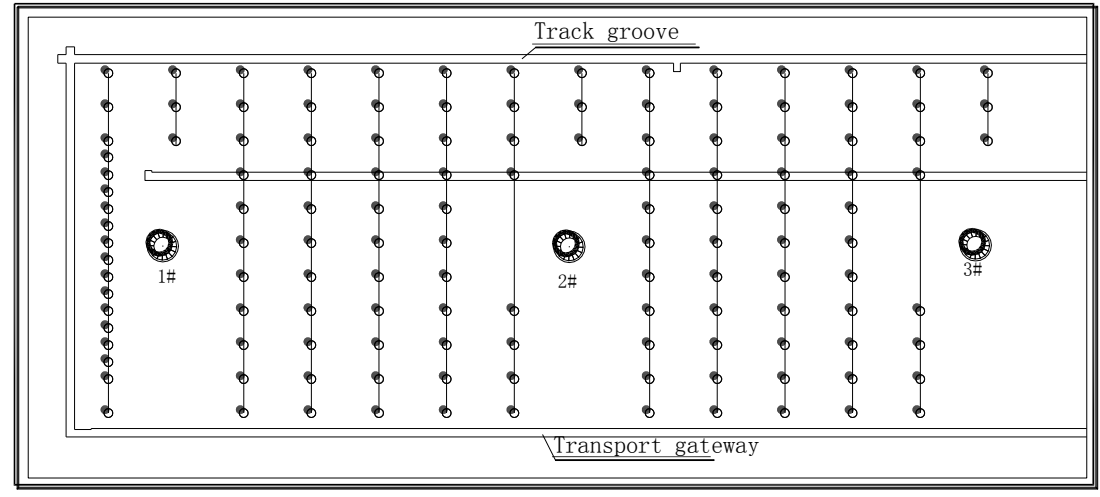

Fig. 5 layout plan of through-layer drilling 
Analysis of Total Extraction Effect.Up to now, the protective layer working face has been mining $240 \mathrm{~m}$, a total of 1.145 million $\mathrm{m}^{3}$ of gas drainage. In 13-1 coal seam effective pressure relief area in situ measured maximum residual gas content is $3.36 \mathrm{~m}^{3} / \mathrm{t}$, and the protective layer during the mining gas concentration of return air is $0.35 \%$, the surface drilling and through hole drainage adjacent 13-1 coal seam high concentration gas, inhibit the adjacent layer pressure relief gas into the protective layer working face, to ensure the safety of working face.

Comparative Analysis of Extraction Effect Between Two Methods. In order to compare the superiority of the gas control technology of the protective layer during the working face mining and optimize the gas extraction measures, the gas extraction concentration, flow rate and extraction amount were analyzed respectively. Working face to promote gas drainage concentration and flow change curve as shown in figure 6.
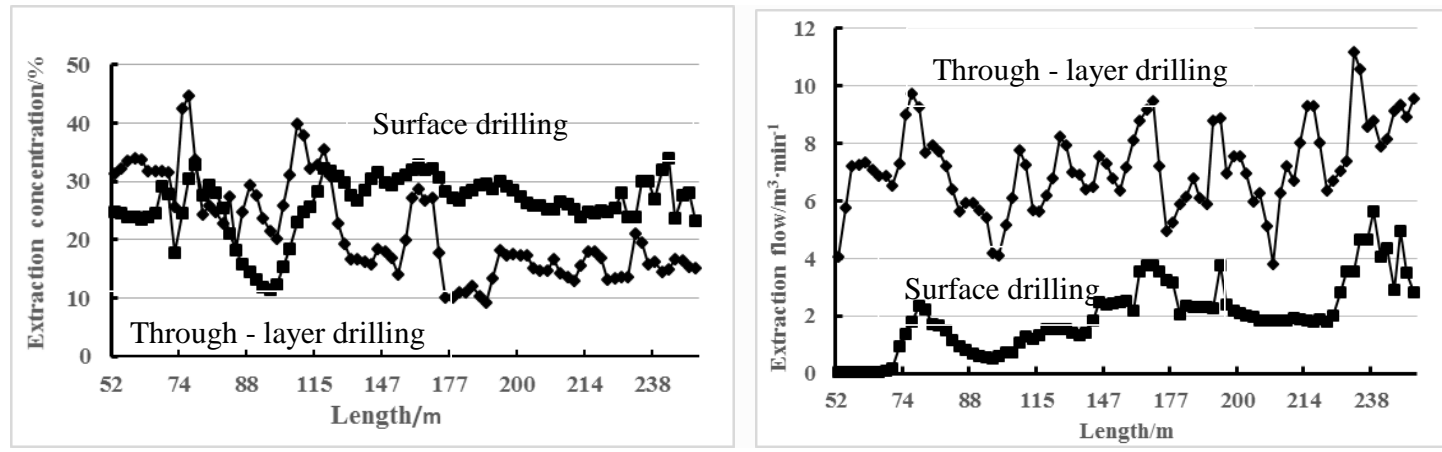

Fig. 6 Variation curve of gas drainage concentration and flow rate of protected layer with working recovery length

From the analysis of drainage flow and concentration, the drainage concentration of surface drilling gas is relatively high, generally $30 \%$, drainage flow is $1 \sim 2 \mathrm{~m}^{3} / \mathrm{min}$, the maximum $5.64 \mathrm{~m}^{3} / \mathrm{min}$, drainage concentration and flow is stable; The drainage concentration and flow rate of through-hole drilling vary greatly, the concentration fluctuates between $10 \%$ and $20 \%$, and the flow rate fluctuates between $4 \mathrm{~m}^{3} / \mathrm{min}$ and $11.5 \mathrm{~m}^{3} / \mathrm{min}$. From the analysis of the total drainage, it can be seen that the gas volume of 13 - 1 coal seam is $1,076,600 \mathrm{~m} 3$, accounting for $90.41 \%$ of the total drainage volume; 1 \# surface drilling drainage 13-1 coal seam gas $100000 \mathrm{~m}^{3}$ accounted for $9.59 \%$ of the total drainage.

From the above extraction data analysis, it can be seen that the high-concentration and lowflow gas extracted by the surface drilling, the low-concentration and high-flow gas extracted by the through-layer drilling are mainly due to the negative extraction pressure of $15 \mathrm{kpa}$ of the surface drilling and through-layer drilling. under the condition of the same negative extraction pressure, the negative extraction pressure is only drawn to the gas around the through-layer drilling area of 50m without construction. the pressure relief gas outside the area is extracted by the through-layer hole, and the extraction capacity and range are larger than the extraction range of the surface drilling. most of the gas in the 13-1 coal seam is extracted by the through-layer drilling, resulting in relatively poor extraction effect of the surface drilling, and the two have mutual influence, and should be treated

Optimization Design of Gas Extraction in Protected Layer. Optimization design of gas drainage by protective layer according to gas drainage practice shows that surface drilling has the characteristics of large drainage range, good effect, long period and not limited by underground roadway conditions ${ }^{[3]}$. Combining with the roadway layout of protective layer 
working face, through adjusting the layout range and spacing of through-layer drilling, the drainage measures by protective layer are optimized, that is, surface drilling drainage is mainly adopted, and through-layer drilling drainage is assisted to control gas by protective layer.

Accord to that $\mathrm{o}$ - ring distribution of the overlying rock fissure in the goaf after the mining of the protective layer work face, the effective pressure relief drainage radius of the surface drilling is in an elliptical shape, namely, the effective drainage radius along the advancing direction of the working face is larger than the effective drainage radius of the vertical working face tendency. According to the field investigation results, the pressure relief drainage radius of the mine surface drilling in the working face advancing direction is $200 \mathrm{~m}$, and the pressure relief drainage radius in the vertical advancing direction is $110 \mathrm{~m}$.. Therefore, in the surface drilling pressure relief extraction radius range is not in the construction through the layer drilling, only in the surface drilling extraction relatively weak area targeted construction through the layer drilling, extraction by protective layer gas. The drainage range of surface drilling and the arrangement of through-layer drilling are shown in fig. 7.

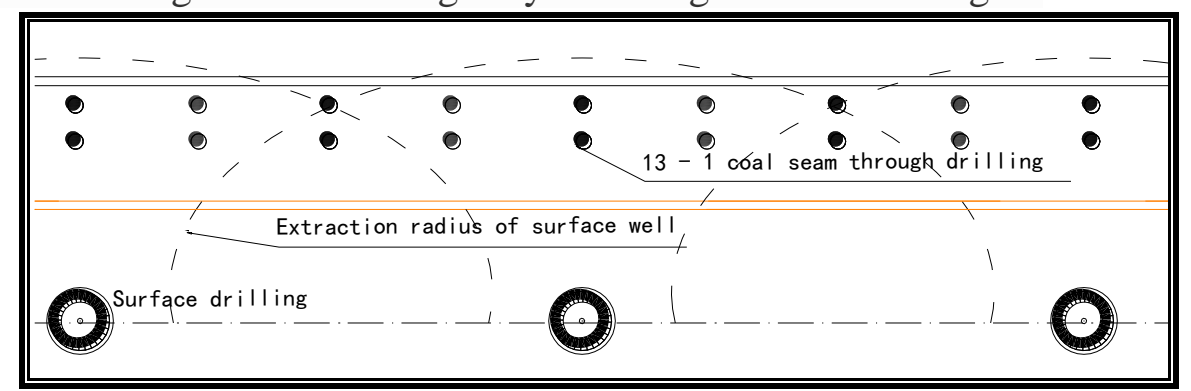

Fig. 7 Layout plan of through-layer drilling

The variation law of drainage flow rate of $1 \#$ and $2 \#$ surface wells with working face advancing before and after optimization of through-layer drilling is shown in fig. 8. As can be seen from the figure, the gas drainage net quantity of well $2 \#$ is maintained at $7 \sim 8 \mathrm{~m}^{3} / \mathrm{min}$; Before optimizing the layout of through-hole drilling, 1 \# drilling also has a similar rule, but the gas extraction net amount is relatively low, generally maintained at $2 \sim 3 \mathrm{~m}^{3} / \mathrm{min}$. Through comparative analysis, the drainage effect of through-layer drilling on surface drilling is indeed affected. through adjusting the arrangement of through-layer drilling, the drainage effect of surface drilling is improved. Therefore, the mine adopts the ground drilling drainage is given priority to, through the layer drilling drainage is complementary to the way is suitable for gas control by protective layer, on the premise of ensuring safety in production, reduce the drilling quantity, reduce the cost of gas control.

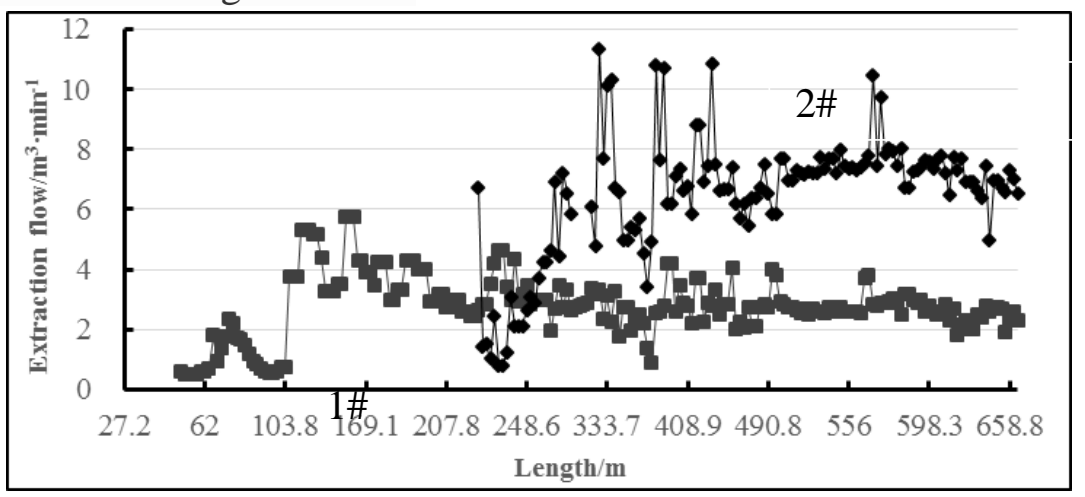

Fig. 8 comparison diagram of drainage flow of surface drilling before and after optimization of cross-layer drilling 


\section{Conclusion}

Through the analysis of the gas drainage effect of protective layer during mining, it is shown that the gas content of the protective layer is reduced to $3.36 \mathrm{~m} 3 / \mathrm{t}$ by the combination of surface drilling and through-hole drainage, which effectively inhibits the pressure relief gas from flowing into the protective layer, and can avoid the gas overrun of the working face, but the drainage effect affects each other, and the gas control cost is high. On the basis of determining and analyzing the pressure relief drainage radius of the surface drilling, only the area with weak drainage by the surface drilling is provided with the through-layer drilling, which can avoid the drainage influence of the surface drilling and the through-layer drilling, enhance the drainage effect of the surface well, inhibit the gas emission of the protective layer, reduce the drilling quantity and reduce the gas control cost, realize the safe and efficient mining of the mine mainly by the surface drilling drainage, and the through-layer drilling auxiliary drainage mode is popularized and applied in the mine.

\section{References}

[1] Institute of gas ventilation, fire prevention and control safety - prediction method of mine gas emission Development and contribution of law [J]. coal mine safety, 2003,34 (supplement ):10-13.

[2] YU Q-i xiang, WANG Kai, YANG Sheng-qiang.Study on patter and control of gas emission at coal face in China[J]. Journal of China University of Min-ing \& Technology, 2003,29(1):9-14.

[3] Cheng Yuanping, Fu Jianhua, Yu qixiang. China's coal mine gas extraction technology development [J]. journal of mining and safety engineering. 2009,26 (2):127 -139.

[4] Cheng Yuanping, Zhou Deyong, Yu qixiang, et al. Study on extraction and emission law of pressure relief gas in protective layer [J]. journal of mining safety engineering. 2006,23 (1): 12-18.

[5] Sun Mingchuang, Bai Xinhua. High gas outburst working face gas control measures and effect analysis [J]. coal engineering. 2013. (5). 